\title{
Mobile Learning in Teacher Education
}

\section{Tony Hall ${ }^{1} \cdot$ Cornelia Connolly $^{1}$}

Published online: 7 November 2019

(C) Association for Educational Communications \& Technology 2019

Mobile learning offers possibilities to enhance teaching and support innovation in schools, and beyond - in non-formal and elective educational settings. The portability of this technology can enable novel synergies of formal and informal learning through BYOD and 1:1 mobile deployment; new creative apps; and also the extensible nature of increasingly sophisticated and powerful, portable devices.

A significant mobilising context for lasting and sustainable educational change and innovation is teacher education, across the continuum: from initial training and professional induction for teachers, to lifelong learning and educational research, with and for teachers (OECD 2019).

However, education and teacher education are complex systems, constituted of myriad aspects, agendas and architectures. This pertains particularly when we look across jurisdictions, and the diverse and divergent nature of teacher education internationally. Consequently, to adopt the concept and language of Penuel $(2015,2019)$, how can we engage in infrastructuring for effective mobile learning, and do so in the important and contiguous domains of initial teacher education and teacher professional development?.

The purpose of this special issue has been to issue a call for papers that highlight key features of infrastructuring in relation to mobile learning within teacher education and related areas. In recent years, particularly in the context of teacher education, mobile learning research is becoming more coordinated. For example: European research projects, such as MTTEP: Mobilising and Transforming Teacher Education Pedagogies; and DEIMP: Designing and Evaluating Innovative Mobile Pedagogies are endeavouring to advance a coherent research agenda, specifically in mobile teacher education. Further,

Tony Hall

tony.hall@nuigalway.ie

Cornelia Connolly

cornelia.connolly@nuigalway.ie

1 School of Education, National University of Ireland, Galway, Ireland research networks (e.g. IMoLeNTE (The International Mobile Learning Network for Teachers Educators); dedicated international conferences (MiTE: Mobile Technology in Teacher Education (now in its 6th year); and bespoke, awardwinning programme designs are emerging (e.g. NUI Galway's Máistir Gairmiúil san Oideachas (Irish language version of the Professional Master of Education), which are attempting to impact in a coordinated way upon teacher education and the possibilities for mobile learning in this important context (Burden and Naylor 2019; O Grádaigh et al. 2019).

Perhaps first the most important and foundational aspect of effective educational design is a sound ontological basis, and thereupon the sensitivities and principles that can help to guide us in optimizing the impact of innovations with technology.

The opening article by Kearney at al. generated principles for mobile learning, predicated on an extensive literature review, which is followed by engaging with the key stakeholders to identify which principles they perceive as most important. The paper furthermore introduces a novel approach: the application of a Best/Worst Scaling survey to interrogate mobile learning principles, a pioneering use of this methodology in the field. The article highlights in particular the importance of authenticity for mobile learning experts and the salience of agency, i.e. personalisation and customisation, among practising teachers. While developed to support app development within an EU transnational, consortium project, principles emerging from this research should be very helpful to all educational designers and technologists who are interested to deploy mobile learning in teacher education. The article sets the tone well for the special issue as a whole, highlighting key stakeholders' priorities in terms of the principled use of mobile learning in education.

A fundamental, developmental component of teacher education programmes internationally is reflection, and specifically: the development of teachers' capacity for reflective practice (OECD 2005). So when we reflect on mobile technology in teacher education, it raises questions with respect to whether, and how mobile devices may affect and enhance pre-service teachers' own capacity for reflection. The second article in the 
special issue by Parmigiani and colleagues looks at how mobile devices can help to mediate innovative and interactive spaces for learning and reflection, which challenge the boundaries between formal and informal learning. The research reported in this paper also highlights how a specific model and mobile learning design can impact upon, and potentially enhance teachers' capacity for reflective practice. It affords the reader insight into how mobile learning can augment teacher education, particularly in respect of professional reflection among pre-service teachers.

One-to-one initiatives are an important enabler in the development of mobile learning in education broadly, and in teacher education in particular, especially in terms of infrastructuring the capacity for teachers and pupils to have their own mobile device to-hand, to support learning, teaching and assessment. A critical aspect of the uptake and success of 1:1 mobile learning in practice in schools is teachers' technological self-efficacy, alongside their capacity and confidence to use technology innovatively and effectively in their classrooms. The third paper in the special issue, by Kwon and colleagues, investigates teachers' beliefs and self-confidence in terms of mobile technology integration in schools. Methodologically, this was done through administering a survey to 57 teachers in middle schools where there are 1:1 mobile initiatives. Critically, this paper offers important insights into environmental challenges; usability and ease-of-use; and teachers' personalised efficacy, highlighting the prevailing impact and importance of these factors in the successful deployment of mobile learning in classrooms.

Mobile video coaching remains a 'Holy Grail' of teacher education and professional development. It holds the promise of enriching teacher education, while at the same time mitigating potentially unnecessary travel and costs. Furthermore, mobile video coaching offers the opportunity to engage with the day-to-day situatedness of real classrooms, and thus support principles of authenticity in how we tutor and support the development of teachers' professional capacities and competences. However, how can mobile video coaching be undertaken in a manner that upholds and preserves the quality and standards that are imperative in education and learning, particularly in the context of teacher education? The paper by van der Linden and colleagues, offers the reader a powerful way forward in this context. Using conjecture mapping(Sandoval 2014), this paper outlines for the reader the signature elements for design and enactment that need to be attended to in the codesign of environments in which mobile video coaching may flourish for teacher education and professional development. The paper suggests a robust, systematic design framework, which can be used to develop mobile video coaching to enhance teacher education. The paper by Mac Mahon et al. outlines an exemplar approach for remote supervision in practice. Employing a qualitative case study methodology, this research illustrates how mobile learning can be deployed within an initial teacher education context to achieve the key dual objectives of (1) enhancing the professional learning of preservice teachers; and (2) supporting novitiate school placement tutors. Not only does the paper exemplify how mobileenabled classroom observation and feedback can mitigate the challenges faced by teacher educators (principally, the paucity of time and pressures of undertaking school placement visits at distance), it shows how judicious and principled use of mobile technology can indeed enhance the experience of school placement, for students and tutors. This paper makes for essential and insightful reading for all teacher educators and educational technologists interested in remote school placement supervision, in the initial teacher education and professional education disciplines.

The paper by Handal and colleagues outlines key issues in understanding and addressing how pre-service teachers (PSTs)learn mobile learning. Engaging with 149 fourth-year PSTs, the researchers examined the effect of their perceptions in terms of the adoption of mobile learning in classrooms. In order to promote and advance pre-service teachers' adoption of mobile learning into their practice in classrooms, the paper suggests practical use of mobile devices and technologies in the context of real-life projects and cross-disciplinary mobile-enabled activities. Particularly, it highlights the need to support teachers towards adoption of mobile devices, where they are seen as an authentic pedagogical resource to be used within one's teaching, rather than being unduly concerned with the technology per se. The paper also introduces a continuum of adoption and conceptual frameworks for understanding the level of use of mobile devices by PSTs and their perspectives in relation to the educational technology. The research shows how PSTs' pedagogical beliefs are context-sensitive, pointing to the importance of future qualitative studies to unpack and explore further their beliefs, as situated in the professional setting of school.

The paper by Bai offers insights from pre-service teacher education for elementary schools, highlighting the importance of attending critically to the pedagogical purpose of specific educational apps. This can help to maximise the potential impact of these technologies on learning and teaching in the primary school context. This is an area that arguably demands greater attention: supporting pre-service teachers to select and use apps, and mobile software that will provide the greatest benefit to learning in the classroom.

The paper also suggests the importance of modelling best practice in mobile learning within the teacher education programme, as this can potentially influence significantly the efficacy of mobile learning use by pre-service teachers when they themselves enter the classroom as mobile educators.

The eighth paper in the special issue, by Hicks and Bose, outlines how we can potentially design teacher education programmes systematically to incorporate innovative mobile learning. Understanding curriculum design in teacher education and how this can be effectively augmented with mobile 
technologies are key aspects of mobilising teacher education, in order that pre-service teachers develop their confidence and competence in using novel mobile educational technologies in the classroom. The paper enumerates how an integrated design framework can be deployed to support the enhancement of a teacher education programme through the integration of mobile learning technology, in ways that are constructively aligned with educational priorities and standards.

In their paper, Panckhurst and Cougnon report research examining young people's digital practices. Alongside teachers' use, how young people are using technologies prevails significantly upon how mobile learning is enacted in schools. This pertains especially in contexts where there are considerable fears about increasing screen-time and the impact of mobile technology and social networks on young people, which has led to the prohibition of mobile devices in schools in certain jurisdictions. The paper provides nuanced insight into the potential and positive impact that digital technology, including mobile devices, can have in youth culture. This includes the development of language competencies, and in particular skills pertaining to pragmatics and semantics. Interestingly the research shows how young people might prefer to read on paper, rather than on screens, (although their reading increasingly seems to be screen-based). The paper reports research which helps potentially to inform our understanding of mobile devices as utilised within young people's lived, linguistic practices and socio-cultural contexts - very important perspectives in understanding the possibilities for mobile learning in education in general, and in teacher education more specifically.

How can we know which are the most optimal pedagogical approaches, mediated by mobile technology? How can we conceptualise, understand, evaluate and enhance the mobile educational practices that teachers design for, and enact in their classrooms? If we seek to integrate and promote mobile learning in teacher education and thus schools, (and do so in ways that evidentially enhance learning), we need a framework to help us design mobile learning and, or evaluate its impact. Further, we need to be able to do this in ways that are bespoke for the type of technology being used in the classroom, based on the particular, signature affordances of mobile devices and infrastructures.

The special issue of TechTrends on Mobile Learning in Teacher Education concludes with the paper by Kearney and colleagues, which outlines a further validated iPAC framework. Comprising the three key overarching dimensions of personalisation, authenticity and collaboration (PAC), this enhanced iPAC model affords a robust and rigorous framework to support the design and evaluation of mobile learning innovations, in teacher education and in schools.
The papers included in this special issue suggest exemplars of conceptual tools, methodologies, and systematic approaches to the design, deployment and evaluation of mobile learning for teacher educators. The research collected here offers insights into salient aspects of infrastructuring in the context of the integration and promotion of mobile learning in teacher education. Together they illustrate a range of ways that mobile technology can be introduced and used within initial teacher education, to enhance professional learning critically, in both a principled and participatory fashion. While the field of mobile teacher education is still emerging and cohering around key concepts (e.g. iPAC) and technologies (e.g. iPad), this special issue potentially provides a touchstone reference for the domain as it moves forward as an important area of research and development within educational technology.

\section{References}

Burden, K., \& Naylor, A. (Eds.). (2019). Transforming teacher education with Mobile technologies. UK: Bloomsbury In press.

Organisation for Economic Co-operation and Development (OECD). (2019). A flying start: Improving initial teacher preparation systems. Available online: doi:https://doi.org/10.1787/cf74e549-en. Last accessed: $9^{\text {th }}$ August 2019.

Organisation for Economic Co-operation and Development (OECD). (2005). Teachers matter: Attracting, developing and retaining effective teachers. Paris: Author Retrieved from http://www.oecdilibrary.org/education/teachers-matter-attracting-developing-andretaining-effective-teachers 9789264018044-en.

Grádaigh, Ó., Mac Mahon, S. B., Ní Ghuidhir, S., \& Hall, T. (2019). Mobilising teacher education in Ireland: Infrastructuring the MiTE ecosystem for learning by collaborative design. In K. Burden \& A. Naylor (Eds.), Transforming teacher education with Mobile technologies. UK: Bloomsbury In press.

Penuel, W.R. (2015). Infrastructuring as a Practice for Promoting Transformation and Equity in Design-Based Implementation Research. Keynote presented at the $11^{\text {th }}$ Annual International Conference of the International Society for Design and Development in Education (ISDDE), University of Colorado, Boulder, CO, September 22, 2015. Retrieved on 13/01/2019 from from: http://learndbir.org/talks-and-papers/infrastructuring-as-apractice-for-promoting-transformation-and-equity-in-design-basedimplementation-research-2015.

Penuel, W. R. (2019). Infrastructuring as a practice of design-based research for supporting and studying equitable implementation and sustainability of innovations. Journal of the Learning Sciences.https://doi.org/10.1080/10508406.2018.1552151.

Sandoval, W. (2014). Conjecture mapping: An approach to systematic educational design research. Journal of the Learning Sciences, 23(1), 18-36. https://doi.org/10.1080/10508406.2013.778204.

Publisher's Note Springer Nature remains neutral with regard to jurisdictional claims in published maps and institutional affiliations. 